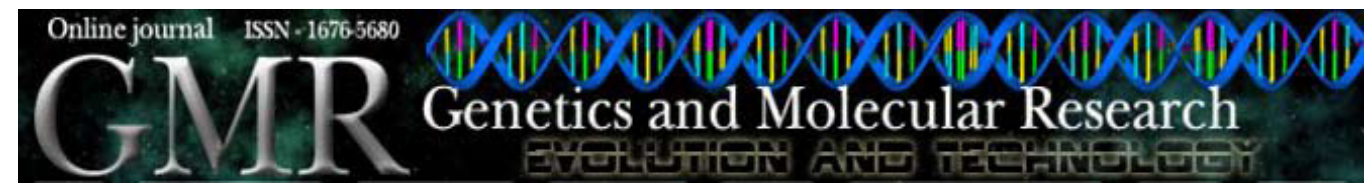

Short Communication

\title{
Abnormal hemoglobin phenotypes in carriers of mild anemia in Latin America
}

\author{
P.J.A. Zamaro and C.R. Bonini-Domingos \\ Departamento de Biologia, Laboratório de Hemoglobinas e Genética das \\ Doenças Hematológicas, Instituto de Biociências, Letras e Ciências Exatas, \\ Universidade Estadual Paulista, São José do Rio Preto, SP, Brasil \\ Corresponding author: C.R. Bonini-Domingos \\ E-mail: claudiabonini@sjrp.unesp.br
}

Genet. Mol. Res. 9 (1): 425-428 (2010)

Received November 29, 2009

Accepted December 23, 2009

Published March 9, 2010

ABSTRACT. We looked for abnormal hemoglobins in blood samples sent for diagnosis of anemia. Identification of the hemoglobins was made using electrophoretic, chromatographic and molecular procedures. The 2020 blood samples were of patients from various regions of Brazil and from some other Latin American countries. Among the abnormal hemoglobins that we found, $3.5 \%$ are known to be rare, while $51 \%$ had an electrophoretic profile similar to that of $\mathrm{Hb} \mathrm{S}$ at alkaline $\mathrm{pH}$. Differentiation was possible only by combining electrophoretic and chromatographic methods. Hb Hasharon, an alpha globin chain mutant, was the most frequently found variant hemoglobin; it accounted for $14.3 \%$ of the abnormal DNA samples. The other abnormal hemoglobin phenotypes displayed distinct electrophoretic profiles; most of them migrated faster than $\mathrm{Hb} \mathrm{A}$. The frequencies of the different abnormal hemoglobin profiles that we found reflect the miscegenation of the Latin American population and indicate the importance of hemoglobin studies using various methods in combination for accurate diagnosis and appropriate counseling of carriers and their families.

Key words: Abnormal Hb; Polymorphism; Anemia; Thalassemia; Hemoglobinopathies 
Human hemoglobin $(\mathrm{Hb})$ is composed of four subunits, each one containing a globin chain and an iron-porphyrin heme moiety. The primary functional role of hemoglobin is the transport of oxygen from the lungs to the body tissues, and $\mathrm{CO}_{2}$ in the opposite direction. The normal hemoglobin molecule contains two different types of globin chains, with each pair represented in the functional tetramer. This is constituted by four polypeptide chains, two of them called the alpha type with 141 amino acids, and the other two called the beta type with 146 amino acids (Lehman and Huntsman, 1974; Bunn and Forget, 1986).

The abnormal hemoglobins are essentially due to alterations in the structural genes that produce hemoglobin molecules with different biochemical characteristics compared to the normal hemoglobin and consequently give rise to variant hemoglobins (Bunn and Forget, 1986; Bonini-Domingos, 2006).

Most of the structural hemoglobin variants originate from a single amino acid substitution, as a result of a change in the nucleotide sequence. The structural alterations, which affect the physical and chemical activities of the molecule, depend on the extent of the mutational process and the loci at which they occur. More than 1024 hemoglobin variants have been identified, and some of them are associated with hematological disorders such as anemia or polycythemia; another is asymptomatic and found in large population studies (Clark and Thein, 2004). The purpose of the present study was to determine the different abnormal hemoglobins in the blood samples designated for anemia study.

Blood samples were collected after consent from 2020 adult individuals, by venous puncture in a tube with 5\% EDTA as anticoagulant; they were from Southeast, South, Northeast, and Center West Brazil, and Colombia.

The analyses for the identification of abnormal hemoglobins included the following screening tests: osmotic resistance in $0.36 \% \mathrm{NaCl}$ (Silvestroni and Bianco, 1975), red blood cell analysis to evaluate size and shape and hemoglobin content (Bonini-Domingos, 2006), and electrophoretic profile at alkaline $\mathrm{pH}$ (Marengo-Rowe, 1965). In order to confirm alpha thalassemia, the following tests were carried out: electrophoresis at neutral $\mathrm{pH}$ for identification and quantification of $\mathrm{Hb} \mathrm{H}$ (Dacie and Lewis, 1985) and determination of $\mathrm{Hb} \mathrm{H}$ inclusion bodies using brilliant cresyl blue (Papayannopoulos and Stamatoyannopoulos, 1974).

The identification of variant hemoglobins was performed by electrophoresis at acid $\mathrm{pH}$, which is specific for differentiating some kinds of hemoglobins that co-migrate at alkaline $\mathrm{pH}$ (Vella, 1968); electrophoresis of polypeptide chains on cellulose acetate at alkaline $\mathrm{pH}$, and polyacrylamide gel electrophoresis at acid $\mathrm{pH}$, specific for the identification of abnormal polypeptide chains, a molecular pre-analysis essential for the determination of the abnormal fraction (Schneider, 1974; Alter et al., 1980); high performance liquid chromatography with automated VARIANT instrumentation (Bio-Rad Laboratories), and beta thalassemia short program, which allows the characterization and quantification of different hemoglobin fractions in a sample, taking into account the percentage values and retention time, compared to specific calibration values, which are established by the manufacturer (Eastman et al., 1996).

After the procedures described above, and with the mutant suspicions defined, molecular tests were performed to confirm $\mathrm{Hb} \mathrm{S}, \mathrm{Hb} \mathrm{C}$ and $\mathrm{Hb}$ D-Los Angeles, using the polymerase chain reaction-restriction fragment length polymorphism (PCR-RFLP) technique. Genomic DNA was isolated from whole blood by phenol-chloroform extraction and ethanol precipitation (Pena et al., 1991), and amplification was carried out according to specific protocols for each mutant previously described (Zamaro et al., 2002). The amplification products were submitted to RFLP analysis, using restriction enzymes according to the specifc mutation: DdeI, BseRI and EcoRI. 
Among the 2020 samples analyzed of mild anemia carriers, $24.5 \%$ showed normal hemoglobin phenotypes, and $75.5 \%$ altered phenotypes, which is explained by the sample characteristics. Among the defined alterations, 35.2\% were alpha thalessemia carriers, $2.4 \%$ beta thalassemia heterozygotes, $21.0 \%$ interactions between variant hemoglobins and thalessemia, and $16.9 \%$ variant $\mathrm{Hb}$, as described in Table 1 . Alpha thalassemia, confirmed with specific tests, was the most frequent phenotype (35.2\%), confirming the high incidence of this alteration in the Latin American population.

Table 1. Percentage of each alteration of $\mathrm{Hb}$ found in the analyses of 2020 samples sent for anemia study.

\begin{tabular}{lc}
\hline Alteration & Frequency (\%) \\
\hline Alpha thalassemia & 35.2 \\
Beta thalassemia & 2.4 \\
Interactions & 21.0 \\
Abnormal Hb & 16.9 \\
\hline
\end{tabular}

The group with the most frequent $\mathrm{Hb}$ variants in Brazil includes $\mathrm{Hb} \mathrm{S}, \mathrm{Hb} \mathrm{C}$ and $\mathrm{Hb}$ D-Los Angeles, where Hb D-Los Angeles (1.6\%) stands out as the third most common hemoglobin variant in the group analyzed, confirming the data reported by Leoneli (2001).

In this total analysis, less frequent $\mathrm{Hb}$ phenotypes were also observed in the Brazilian population. In this group, $51 \%$ displayed an electrophoretic migration pattern similar to that of $\mathrm{Hb}$ $\mathrm{S}$ at alkaline $\mathrm{pH}$. The other hemoglobins showed different electrophoretic patterns, and most of them showed fast migration, beyond $\mathrm{Hb} \mathrm{A}$. The diversity of these hemoglobins was only detectable with the combined methods, with different electrophoretic techniques and chromatographic analyses, which were very important to determine the likely phenotype. Table 2 shows the values obtained for the relative and absolute frequencies of each hemoglobin variant phenotype found.

Table 2. Absolute and relative frequencies of phenotypes of rare hemoglobins in the variant Hb group analyzed.

\begin{tabular}{lc}
\hline Phenotype of rare $\mathrm{Hb}$ & Absolute frequency \\
\hline Hb Hasharon & 10 \\
Hb Korle-Bu & 4 \\
Hb Stanleyville & 2 \\
Hb D-Iran & 2 \\
Hb Lepore & 3 \\
Hb Q-India & 1 \\
Hb E & 5 \\
Hb E-Saskatoon & 1 \\
Hb Köln & 2 \\
Hb B2 & 4 \\
Hb J-Oxford & 4 \\
Hb I & 1 \\
Hb Canden & 2 \\
Hb Q-Thailand & 1 \\
Not suspicious & 28 \\
\hline
\end{tabular}

The most frequent phenotype in the group of rare hemoglobins was Hb Hasharon in heterozygosis, an alpha globin chain mutant, with an electrophoretic profile similar to that of $\mathrm{Hb} \mathrm{S}$ at alkaline $\mathrm{pH}$, which was $14.3 \%$ of the total samples analyzed in this group. This phenotype is frequently found in populations of Mediterranean origin, confirming the strong European influences in the composition of the Latin American population (Huisman et al., 2009). 
We should also emphasize that the group of interactions between variant hemoglobins and thalassemias (21\%), resulting in clinical and phenotypic characteristics, is not expected in carriers of variant hemoglobins, which are frequently asymptomatic. In $40 \%$ of the cases analyzed, it was not possible to determine one suspected phenotype, for lack of complete information in the literature and of electrophoretic migration maps for one of the hemoglobinopathies to be used in the routine diagnoses.

The frequencies of different profiles of abnormal hemoglobins that were found reflect the degree of miscegenation in Latin America and give evidence of the importance of establishing electrophoretic and chromatographic hemoglobin patterns and strategies for molecular analyses of the Latin America population, besides developing studies with combined methods aimed at accurate diagnosis.

\section{ACKNOWLEDGMENTS}

We thank Lara Castellani and Prof. Dr. Alvaro Hattnher for help with preparing the English manuscript. We also thank the Brazilian foundation Conselho Nacional de Desenvolvimento Científico e Tecnológico (CNPq) for a post-graduate scholarship and Bio-Rad for technical support.

\section{REFERENCES}

Alter BP, Goff SC, Efremov GD, Gravely ME, et al. (1980). Globin chain electrophoresis: a new approach to the determination of the G gamma/A gamma ratio in fetal haemoglobin and to studies of globin synthesis. $B r . J$. Haematol. 44: 527-534.

Bonini-Domingos CR (2006). Metodologias Laboratoriais para o Diagnóstico de Hemoglobinopatias e Talassemias. Editora HN, São José do Rio Preto.

Bunn HF and Forget BG (1986). Hemoglobin: Molecular Genetic and Clinical Aspects. Saunders, Philadelphia.

Clark BE and Thein SL (2004). Molecular diagnosis of haemoglobin disorders. Clin. Lab. Haematol. 26: 159-176.

Dacie JV and Lewis SM (1985). Practical Haematology. 6th edn. Churchill, London.

Eastman JW, Wong R, Liao CL and Morales DR (1996). Automated HPLC screening of newborns for sickle cell anemia and other hemoglobinopathies. Clin. Chem. 42: 704-710.

Huisman HJ, Carver MFH and Efremov GD (2009). HbVar: A Database of Human Hemoglobin Variants and Thalassemias. Summaries and Mutation Categories. Pennsylvania University USA, and McMaster University, Canada. Available at [http://globin.bx.psu.edu/hbvar/menu.html]. Accessed May 2009.

Lehmann H and Huntsman RG (1974). Man's Haemoglobins. North Holland Publishing Company, Amsterdam.

Leoneli GG (2001). Hemoglobina D - Caracterização Eletroforética e Molecular. Master's thesis, Instituto de Biociências, Letras e Ciências Exatas, Universidade Estadual Paulista, São José do Rio Preto.

Marengo-Rowe AJ (1965). Rapid electrophoresis and quantitation of haemoglobins on cellulose acetate. J. Clin. Pathol. 18: 790-792.

Papayannopoulos R and Stamatoyannopoulos G (1974). Stains for Inclusion Bodies. In: Standardization of Laboratory Reagents and Methodos for Detection of Haemoglobinopathies. Hew publications, Atlanta, 174-178.

Pena SD, Macedo AM, Gontijo NF, Medeiros AM, et al. (1991). DNA bioprints: simple nonisotopic DNA fingerprints with biotinylated probes. Electrophoresis 12: 146-152.

Schneider RG (1974). Differentiation of electrophoretically similar hemoglobins - such as S, D, G, and P; or A2, C, E, and O - by electrophoresis of the globin chains. Clin. Chem. 20: 1111-1115.

Silvestroni E and Bianco I (1975). Screening for microcytemia in Italy: analysis of data collected in the past 30 years. $\mathrm{Am}$. J. Hum. Genet. 27: 198-212.

Vella F (1968). Acid-agar gel electrophoresis of human hemoglobins. Am. J. Clin. Pathol. 49: 440-442.

Zamaro PJA, Canalli AA, Silva Júnior WA and Bonini-Domingos CR (2002). Laboratorial diagnosis for hemoglobin like HbS. [Diagnóstico laboratorial de hemoglobinas semelhantes à HbS]. J. Bras. Patol. Med. Labor. 38: 261-266. 